\title{
Quantification of Organophosphate and Carbamate Pesticide Residues in Maize
}

Ogah C.O. and Coker H.B.

Department of Pharmaceutical Chemistry, Faculty of Pharmacy, University of Lagos, Nigeria.

\section{ARTICLE INFO}

Article history:

Received on: 13/08/2012

Revised on: 29/09/2012

Accepted on:05/09/2012

Available online: 28/09/2012

Key words: Pesticide residue, Maize, Organophosphate,

Carbamate Lagos.

\begin{abstract}
Use of pesticides in agriculture to protect crops against destructive pests often leads to residues of these chemicals in foods. The levels of pesticide residues in food are often determined as a means of assessing appropriate use as well as the potential for human exposure to these chemicals and hence their potential damage to human health. The aim of this study was to determine the concentration of organophosphate and carbamate pesticides in maize samples collected from various markets in Lagos State and compare these values with established safety values. Maize (Zea mays $L$.) samples purchased from different markets in LagosState were analyzed for residues of organophosphate and carbamate pesticides. Analysis was done using gas chromatograph with mass spectrometric detector (GC-MS) after careful extraction and cleanup. It was found that all the maize samples contained residues of one or more organophosphate or carbamate pesticides. Mean concentrations ranged from 12.0 to $1565.4 \mu \mathrm{g} / \mathrm{kg}$. Maximum residue limits (MRL) of some of the pesticides were exceeded in up to $10 \%$ of samples.
\end{abstract}

\section{INTRODUCTION}

Pesticides are chemicals used in agriculture to protect crops against destructive pests and thereby increase food supply. They are also used in public health and other areas for the eradication of disease vectors and other pests. By virtue of their widespread use, pesticides have become a major group of environmental contaminants. When used, pesticides contaminate the environment and accumulate in the food chain thereby posing hazards to human health (Blasco et al, 2003; Leong et al, 2007; Pesticide Action Network, 2001). Pesticides belong to different chemical classes but the major ones are organochlorines, organophosphates, carbamates and pyrethroids. Organochlorines being chemically stable and persistent in the environment have been banned in most countries of the

\footnotetext{
* Corresponding Author

Email: onotsec@yahoo.com

Tel: +2348023148053
}

world but the less persistent classes are widely in use. Organophosphates are highly potent compounds used mainly as insecticides especially in the control of storage insects in food crops. They are very toxic and more often involved in acute poisoning than other classes of pesticides (Collins, 2006; Mansour, 2004). Carbamates on the other hand are less toxic but very effective as insecticides, fungicides, herbicides, nematocides and sprout inhibitors. Figure 1 shows structures of some organophosphate and carbamate pesticides. Organophosphorus and carbamate pesticides exert their toxic action by inhibiting the enzyme acetylcholinesterase (AChE). This enzyme is responsible for the hydrolysis of acetylcholine (ACh), a neurotransmitter that conducts nerve impulses across neuromuscular junctions in the nervous system of vertebrates as well as insects. Inhibition of this enzyme causes accumulation of ACh leading to generalized cholinergic action and resulting in rapid, uncontrolled twitching of voluntary muscles which eventually leads to paralysis, respiratory 
failure and death (Podolska and Napierska, 2006). AChE inhibition by organophosphates is generally irreversible while inhibition by carbamates is reversible. Hence, carbamates are less toxic than organophosphorus compounds. Human exposure to both groups of compounds can be monitored by determining erythrocyte and plasma cholinesterase activity (Guilhermino et al, 2004).
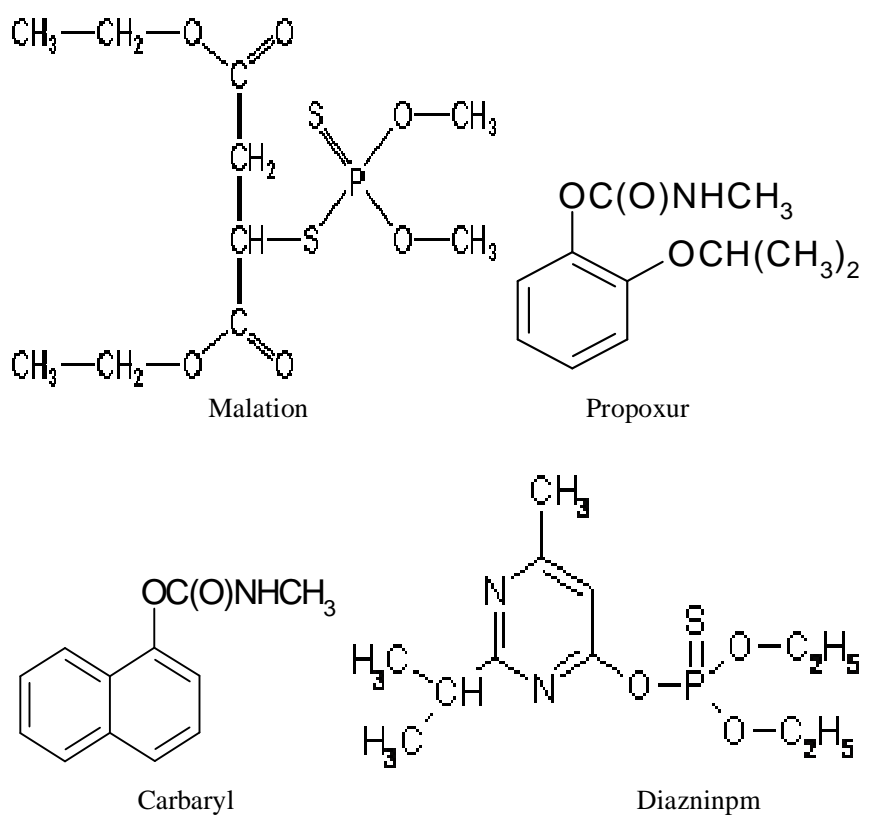

Chronic exposure of humans to low doses of pesticides through air, water and food may lead to chronic toxicity due to accumulation of residues in the body over a long period of time. Possible health problems associated with chronic pesticide toxicity include cancers, congenital malformations, neurological disorders, infertility, blood dyscrasias, impotence, immunological disorders, liver and kidney damage, skin alterations and worsening of existing health conditions (Sesline and Jackson, 1994; Jobling et al, 1995).

Pesticides may also cause acute and sub-acute toxicity arising from exposure to high doses among people who are directly involved in the manufacture, formulation, mixing and application of pesticides or in suicide and homicide cases. This kind of exposure may be through dermal contact, inhalation or accidental ingestion. Symptoms of acute toxicity vary with the individual chemical involved but may generally include dizziness, headaches, sweating, fatigue, numbness, vomiting, cramps, chemical burns of the eye and skin, neurological effects, respiratory tract irritation, liver and kidney damage, coma or death (Koprucu et al, 2006; Turgut, 2007).

Useful to man as they may be, pesticides are poisons and must be properly used to minimize human exposure and reduce health risks. There is therefore governmental regulation of pesticide use all over the world. Analysis of pesticide residues in food is one way of monitoring effectiveness of regulatory control measures and ensuring safety of food. This study will also contribute to building a data base of pesticide residues in food in Nigeria.

\section{MATERIALS AND METHODS}

\section{Chemicals}

The following chemicals and reagents were used in the study;

Standard mixtures of organophosphate and carbamate compounds containing chlorpyrifos, diazinon, dichlorvos, fenitrothion, malathion, parathion, pirimiphos-methyl, carbaryl and carbofuran; 2-chloroanthracene; sodium sulphate; ethyl acetate and hexane. All chemicals and reagents were of analytical grade and above 99\% purity. The solvents were distilled in all-glass apparatus before use.

\section{Collection of Samples}

Samples of white maize (Zea mays L) were purchased from wholesale markets across Lagos State. Seven wholesale markets for grains were chosen to achieve a good geographical spread across the state. The samples were code named and stored in glass bottles with tight covers to protect them from moisture and contamination. They were then stored in the refrigerator until ready for use.

\section{Preparation of Samples}

The samples were cleaned by picking out stones and other extraneous materials. Each sample was thoroughly mixed and a $200.0 \mathrm{~g}$ portion was taken and milled to 20 mesh particle size to produce a good homogenate. The milled samples were then stored in glass bottles with appropriate labels in a refrigerator at $4^{0} \mathrm{C}$. Duplicate portions $(200.0 \mathrm{~g})$ of the samples were stored as whole grains in labeled glass bottles in the refrigerator as backup samples.

\section{Extraction and Clean-up of Samples}

Extraction of samples for the analysis was according to the methods of Wei-Guo et al., 2006 and Sharif et al., 2006 with slight modifications. The milled sample was properly mixed and $2.0 \mathrm{~g}$ was weighed into a $20.0 \mathrm{ml}$ sample vial. Anhydrous sodium sulphate $(1.0 \mathrm{~g})$ was added and mixed with the sample to absorb any moisture present. The sodium sulphate was previously heated at $650^{\circ} \mathrm{C}$ for one hour and stored in a desiccator. Ethyl acetate $(10.0 \mathrm{ml})$ was added to the vial. The mixture was vortex mixed for $5 \mathrm{~min}$ and then allowed to stand for $45 \mathrm{~min}$. It was mixed again and centrifuged for $5 \mathrm{~min}$. at $2500 \mathrm{rpm}$. The supernatant was carefully transferred into a flask. The residue was further extracted twice as described above, using $10.0 \mathrm{ml}$ ethyl acetate each time. The supernatants were combined and reduced to about $5 \mathrm{ml}$ using a rotary evaporator at $35^{\circ} \mathrm{C}$. The solution was then transferred into a sample tube and reduced to about $1 \mathrm{ml}$ under a gentle stream of nitrogen gas at $36^{\circ} \mathrm{C}$. This was then taken for florisil cleanup.

For the clean-up, solid phase extraction cartridges (florisil, 500mg/6ml) were used. Each cartridge was conditioned 
with $5.0 \mathrm{ml}$ of the eluting solvent mixture (hexane/ethyl acetate 50:50) and the sample extract ( $1 \mathrm{ml})$ was loaded on the florisil. The sample tube was rinsed three times with $1.0 \mathrm{ml}$ eluting solvent, and the rinses added to the florisil column. The sample was then eluted with $5.0 \mathrm{ml}$ of the same solvent mixture into a receiving glass tube. The florisil column was rinsed with another $3.0 \mathrm{ml}$ of the eluting solvent mixture into the same receiving glass tube. The eluant was then evaporated to dryness under a gentle stream of nitrogen gas and the residue reconstituted in $1.0 \mathrm{ml}$ ethyl acetate for GC-MS analysis.

\section{Preparation of Calibration Curves}

Stock solutions of pure standards of organophosphate (chlorpyrifos, diazinon, dichlorvos, fenitrothion, malathion, parathion, pirimiphos-methyl) and carbamate (carbaryl and carbofuran) were prepared and then serially diluted to produce different concentrations of the pesticides. Stock standard solutions were stored in amber coloured bottles at $4^{0} \mathrm{C}$ in a refrigerator while working standard solutions were prepared fresh before use.

Standard solutions of the pesticides were run on GC/MS under the set chromatographic conditions and mean peak areas were plotted against concentrations to obtain calibration curves of individual pesticides. The calibration curves for some of the pesticides are shown in Figures 2.
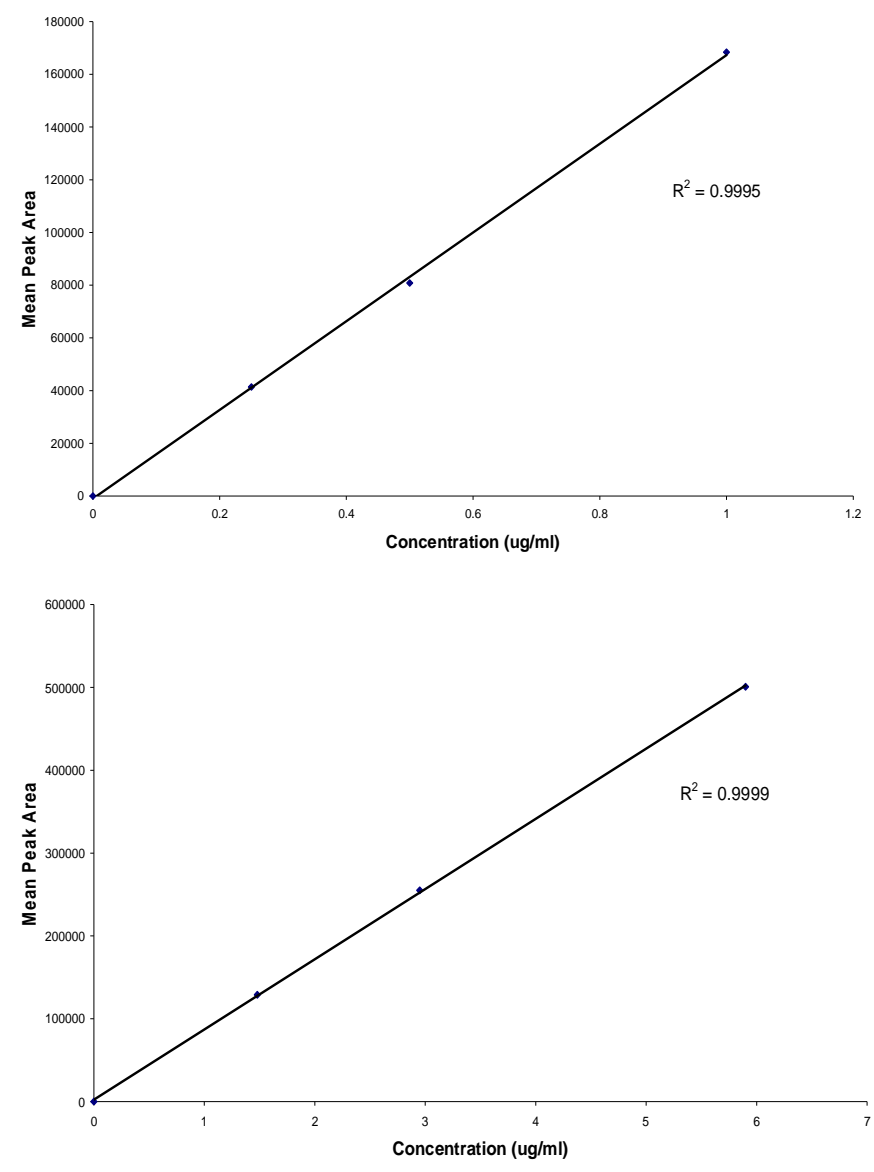

Fig. 2: Standard Calibration Curves for Carbaryl (A) and Chlorpyrifos (B).

\section{Limits of Detection (LOD)}

To determine the limit of detection of the equipment for each pesticide, an air blank sample was run under the experimental conditions to obtain the detector baseline noise. A detectable ion should produce a signal that is at least three times the baseline noise [that is, signal-to-noise $(\mathrm{S} / \mathrm{N})$ ratio $=3$ ] (Maštovská and Lehotay, 2003). The LOD of each pesticide was determined by running serially diluted solutions of the pesticide at the set chromatographic conditions and finding the concentration at which $\mathrm{S} / \mathrm{N}=3$.

Retention times, limits of detection and coefficient of determination of the various pesticides are presented in Table 1.

Table. 1: Names, Retention Times (RT), Limits of Detection (LOD) and Coefficients of Determination of the Pesticides.

\begin{tabular}{llll}
\hline $\begin{array}{l}\text { Pesticide } \\
\text { Name }\end{array}$ & $\begin{array}{l}\text { RT } \\
(\mathbf{m i n} .)\end{array}$ & $\begin{array}{l}\text { LOD } \\
(\boldsymbol{\mu g} / \mathbf{m l})\end{array}$ & $\begin{array}{l}\text { Coefficient of } \\
\text { Determination }\left(\mathbf{r}^{2}\right)\end{array}$ \\
\hline Carbaryl & 7.42 & 0.0075 & 0.9995 \\
Carbofuran & 5.83 & 0.0066 & 0.9999 \\
Chlorpyrifos & 12.28 & 0.0025 & 0.9999 \\
Diazinon & 9.65 & 0.0009 & 1 \\
Dichlorvos & 5.35 & 0.0168 & 0.9999 \\
Fenitrothion & 11.96 & 0.0007 & 0.9985 \\
Malathion & 11.87 & 0.0082 & 0.9999 \\
Parathion & 12.62 & 0.0062 & 0.9984 \\
Pirimiphos-methyl & 11.53 & 0.0014 & 1 \\
\hline
\end{tabular}

\section{Recovery Studies}

Recovery experiments were carried out using blank samples which were selected for spiking. Six levels of mixed pesticide standard solutions were prepared and used for spiking the blank samples. Each standard solution $(1.0 \mathrm{ml})$ was added to $2.0 \mathrm{~g}$ of ground sample to give fortification levels of $0.025,0.25,0.5$, 1.0, 2.0 and 4.0 $\mathrm{gg} / \mathrm{g}$ respectively. Each spiked sample was allowed to stand for six hours and then extracted, cleaned up and analyzed like the test samples. The standard solutions were also run on GC under the same conditions as the spiked samples. Internal standard (2-chloroanthracene) was included in both extract and standard solutions. Peak area ratios of pesticides to those of internal standard were calculated for both standard solutions and spiked samples. The percent recovery of each pesticide was then calculated as follows:

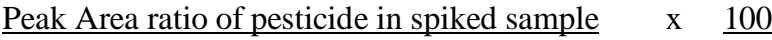

Peak Area ratio of pesticide in standard solution $\quad 1$

\section{Analysis of Pesticide Residue Content $G C-M S$ Conditions}

All compounds were determined and quantified with the aid of a gas chromatograph equipped with a mass-selective detector (GC-MS), an autosampler and a split-splitless injector. The DB-5 fused silica capillary column of $30 \mathrm{~m} \times 0.25 \mu \mathrm{m}$ i.d. $\mathrm{x}$ $0.25 \mu \mathrm{m}$ film thickness was coated with cross-linked $5 \%$ phenyl dimethyl polysiloxane. The carrier gas was helium $(99.999 \%$ purity) at a flow rate of $1.0 \mathrm{ml} / \mathrm{min}$. Oven temperature was maintained initially at $70^{\circ} \mathrm{C}$ for $1 \mathrm{~min}$, increased at $15^{\circ} \mathrm{C} / \mathrm{min}$ to $175^{\circ} \mathrm{C}$, then at $2^{\circ} \mathrm{C} / \mathrm{min}$ to $215^{\circ} \mathrm{C}$, at $10^{\circ} \mathrm{C} / \mathrm{min}$ to $265^{\circ} \mathrm{C}$ and finally 
at $20^{\circ} \mathrm{C} / \mathrm{min}$ to $290^{\circ} \mathrm{C}$ and held for $8 \mathrm{~min}$. Injection volume was $1 \mu \mathrm{L}$, injected in splitless mode at injection temperature of $250^{\circ} \mathrm{C}$.

The mass spectrometer was operated in electron impact (EI) ionization mode with a detector voltage of $700 \mathrm{~V}$, ion source temperature of $200^{\circ} \mathrm{C}, \mathrm{GC}$ interface temperature of $320^{\circ} \mathrm{C}$ and emission current of $150 \mu \mathrm{V}$. Acquisition mode was selected ion monitoring (SIM).

\section{Identification and Quantification}

Pesticide residues were identified if the retention times matched those of the standards and the relative abundances were within $10 \%$ of those of the standards. Identified pesticides were quantified using the external standard method of comparing sample peak areas with those of the pesticide standards under the same conditions. Each sample was analyzed three times and the mean values obtained. The pesticide content of each sample was calculated as:

$$
\text { Pesticide Content }=\frac{\mathrm{As} \times \mathrm{xVf}}{\mathrm{Wt}_{\mathrm{s}} \mathrm{x} \mathrm{CF}}
$$

Where As $=$ peak area of sample

$\mathrm{Vf}=$ final volume of clean extract

$\mathrm{Wt}_{\mathrm{s}}=$ weight of sample extracted

$\mathrm{CF}=$ calibration factor.

The $\mathrm{CF}$ of each pesticide was calculated as

Peak Area of Standard

Total Amount of Standard Injected

\section{RESULTS AND DISCUSSION}

Results of the study show that all the samples contained one or more organophosphate or carbamate pesticides. Maximum concentrations found ranged from 15.8 to $3951.2 \mu \mathrm{g} / \mathrm{kg}$ while mean concentrations were 12.0 to $1565.2 \mu \mathrm{g} / \mathrm{kg}$ for the various pesticides. Residues of pirimiphos-methyl were the most frequently encountered, occurring in $43 \%$ of samples while residues of fenitrithion occurred in $7 \%$ of samples. (Table 2).

Maize (like most grains) is highly susceptible to infestation by weevils and is consequently often subjected to post-harvest treatment with pesticides to maintain good quality during storage and to avoid economic losses. Apart from post-harvest treatment, previously treated or contaminated soil can be a source of these pesticide residues in food crops.

Some of the residues detected were above their maximum residue limits (MRL) but malathion, parathion and pirimiphos-methyl did not exceed their MRL values. The highest violator was chlorpyrifos with $10 \%$ above MRL while fenitrothion was the least with $2 \%$ of samples above MRL. MRL of a pesticide is the maximum concentration of its residue that is legally permitted to remain in food after it has been treated with the pesticide. It is not expected to be exceeded in any food if the pesticide was applied in accordance with directions for its safe use. If a pesticide residue is found to exceed the MRL in a given foodstuff, the food commodity is said to be adulterated because it contains an illegal amount of the residue. The occurrence of pesticides above MRLs in the maize samples is therefore an indication of some form of misuse/abuse of these chemicals. Noncompliance with MRLs can impact negatively on international trade in agricultural produce as each commodity must meet international standards or standards of the receiving country. The goal of monitoring of pesticide use in agriculture should therefore be directed at ensuring appropriate use of recommended products.

Violation of MRLs may lead to accumulation of the chemicals in the body and eventual threat to human health. In addition, there is a potential "cocktail effect" if various pesticides accumulate in the body since the combined effects may be additive or synergistic. This means that even pesticides that were detected at 'safe levels' may eventually pose health hazards to humans due to combined effects of other pesticides also accumulated in the body. There is therefore the need to investigate the potential cocktail effect of pesticide residues in the human body.

Most pesticides are known to be neurotoxic, especially organophosphates and carbamates which inhibit the enzyme acetylcholinesterase. Others have been found to be carcinogenic, teratogenic and to depress immune responses (Mansour, 2004; Koprucuet al., 2006) while some have been identified as endocrine disruptors, meaning that they can affect human growth and reproduction. The toxicological importance of pesticide residue data depends, not only on the residue content of food but also on the quantity of contaminated food consumed and the length of time over which the consumption occurs (Handa et al, 1999 and Peterson, 2000). Therefore, large studies on food consumption patterns of Nigerians and residue contents of other food varieties are required to determine the total intake of pesticide residues and the actual toxicological importance of these residue levels.

Maize as a foodstuff is widely consumed in Nigeria in various forms. Consumers of this commodity should endeavor to wash it thoroughly before other forms of processing to reduce the pesticide residue load at the point of consumption.

\begin{tabular}{|c|c|c|c|c|c|}
\hline Pesticide & $\begin{array}{c}\text { MRL } \\
(\mu \mathrm{g} / \mathrm{kg})\end{array}$ & $\begin{array}{c}\text { Maximum Concentration } \\
(\mu \mathrm{g} / \mathrm{kg})\end{array}$ & $\begin{array}{l}\text { Mean Concentration } \\
(\mu \mathrm{g} / \mathrm{kg})\end{array}$ & $\begin{array}{c}\% \text { Occurrence } \\
\text { (of pesticide in samples) }\end{array}$ & \% Samples above MRL \\
\hline Carbaryl & 50 & 73.5 & 38.3 & 31 & 5 \\
\hline Carbofuran & 100 & 182.2 & 84.1 & 33 & 7 \\
\hline Chlorpyrifos & 50 & 62.1 & 48.7 & 39 & 10 \\
\hline Diazinon & 20 & 30.3 & 21.2 & 25 & 6 \\
\hline Dichlorvos & 2000 & 2367.7 & 1127.2 & 37 & 4 \\
\hline Fenitrothion & 10 & 15.8 & 12.0 & 7 & 2 \\
\hline Malathion & 8000 & 3951.4 & 1565.2 & 27 & 0 \\
\hline Parathion & 50 & 48.2 & 42.6 & 11 & 0 \\
\hline Pirimiphos-methyl & 5000 & 3185.1 & 1455.4 & 43 & 0 \\
\hline
\end{tabular}

Table. 2: Pesticide Residue Concentrations in Maize Samples Versus Maximum Residue Limits of the Various Pesticides. 


\section{CONCLUSION}

There is a high incidence of pesticide residues in maize sold in Lagos markets. Most of the residues were found to be above the maximum residue limits with legal implications and the ranges of concentrations were wide. There is a need for the relevant agency to strictly control the importation, sale, use and disposal of these toxic chemicals.

\section{REFERENCES}

Blasco C., Fernandez M., Pena A., Lino C., Silveira M., Font G. and Pico Y. Assessment of pesticide residues in honey samples from Portugal and Spain. Journal of Agriculture and Food Chemistry. 2003; 51 (27): 8132-8

Collins D. A. A review of alternatives to organophosphorus compounds for the control storage mites. Journal of Stored Products Research. 2006; 42: 395-426.

Guilhermino L., Soares A., Tinoco-Ojanguren R. and Osten J.Effect of pesticide exposure on acetylcholinesterase activity in subsistence farmers from Campeche, Mexico.Archives of Environmental Health. 2004; 3: 1-30.

Handa S., Agnihotri N. and Kulshrestha G. Pesticide Residues: Significance, Management and Analysis. Research Periodicals and Book Publishing House, USA (1999). 1- 31.

Jobling S., Reynolds T., White R., Parker M. and Sumpter J. Chemicals found to mimic human estrogens. Environmental Health Perspectives. 1995; 103: 582-587.

Koprucu S., Koprucu K., Ural M., IspirU. and Pala M. Acute toxicity of organophosphorus pesticide diazinon and its effects on behaviour and some haematological parameters of fingerling European catfish. Journal of Pesticide Biochemistry and Physiology. 2006; 86: 99105 .

Leong K. H., Tan L. B. and Mustafa A. M.. Contamination levels of selected organochlorine and organophosphate pesticides in the Selangor River, Malaysia between 2002 and 2003. Chemosphere. 2007; 66 (6): 1153-1159.
Mansour S.A. Pesticide exposure - Egyptian scene. Toxicology. 2004; 198: 91-115.

Maštovská K. and Lehotay S. Practical approaches to fast gas chromatography- mass spectrometry. Journal of Chromatography A. 2003; 1000: $153-180$.

Pesticide Action Network (2001).The Hazards of Pesticide Use for Man and the Ecosystem. In: Pesticide Action Network (Ed.) Pesticides in Tropical Agriculture - Hazards and Alternatives (pp. 23 -61).

Petersen B.J. Pesticide residues in food: Problems and data needs. Regulatory Toxicology and Pharmacology. 2000; 31:297-299.

Podolska M. and Napierska D.Acetylcholinesterase activity in hosts (herring Clupeaharengus) and parasites (Anisakis simplex larvae) from the southern Baltic.ICES (International Council for the Exploration of the Sea) Journal of Marine Science. 2006; 63(1): 161-168.

Sesline D.H. and Jackson R.J. (1994).The effects of pre-natal exposure to pesticides. In: Needleman H.L. and Bellinger D. (Eds.)Prenatal Exposure to Toxicants: Development Consequence. (pp. 233-248). The John Hopkins University Press, Baltimore.

Sharif Z, Man YB, Hamid NS, and Keat CC. Determination of organochlorine and pyrethroid pesticides in fruits and vegetables using solid phase extraction clean-up cartridges. Journal of Chromatography A. 2006; 1127: 254-261.

Turgut C.The impact of pesticides toward parrotfeather when applied at the predicted environmental concentration.Chemosphere. 2007, 66 (3): 469 - 473.

Zhang WG, Chu XG, Cai HX, An J. and Li CJ. Simultaneous determination of 109 pesticides in unpolished rice by a combination of gel permeation chromatography and florisil column purification, and gas chromatography/mass spectrometry. Rapid Experimental Commun. Mass Spectrom. 2006; 20: 609-617.

How to cite this article:

Ogah C.O. and Coker H.B. Quantification of Organophosphate and Carbamate Pesticide Residues in Maize J App Pharm Sci. 2012; 2(9): 093-097. 